\title{
Disadvantage of Operation Cost in Laparoscopy- Assisted Distal Gastrectomy under the National Health Insurance System in Japan
}

\author{
Yoshiyuki Hoya $^{a}$ Tetsuya Taki $^{a}$ Yujirou Tanaka ${ }^{a}$ Humiaki Yano $^{a}$ \\ Tsuyoshi Hirabayashi $^{a}$ Tomoyoshi Okamoto $^{\text {a Hideyuki Kashiwagi }}{ }^{b}$ \\ Katsuhiko Yanagab \\ Departments of Surgery, ${ }^{a}$ Daisan Hospital, Jikei University School of Medicine, and \\ b Jikei University School of Medicine, Tokyo, Japan
}

\section{Key Words}

Laparoscopy-assisted distal gastrectomy • Gastric cancer • Health insurance $\cdot$ Minimally invasive surgery $\cdot$ Cost benefit

\begin{abstract}
Background: The utility and problems including the socioeconomic aspect of laparoscopy-assisted distal gastrectomy for gastric cancer have not been fully evaluated. Subjects and Methods: We compared open distal gastrectomy and laparoscopy-assisted distal gastrectomy for the clinical benefit, quality of life, and problems of operation cost by the reference documents in which the difference between open distal gastrectomy and laparoscopy-assisted distal gastrectomy was examined in detail. The reference documents retrieved by the key words 'gastric, cancer, laparoscopic, surgery' were 22 in PubMed with the following limits activated: Humans, Clinical Trial, Meta-Analysis, Randomized Controlled Trial, Review, English, Core clinical journals, published in the last 10 years. Results: The operation time of laparoscopy-assisted distal gastrectomy is longer than that of open distal gastrectomy. However, if skilled, the blood loss of laparoscopy-assisted distal gastrectomy is less, the hospitalization days and the duration of fasting after laparoscopy-assisted distal gastrectomy are shorter than those after open
\end{abstract}

distal gastrectomy. The number of excised lymph nodes and the incidence of postoperative complications were similar between laparoscopy-assisted distal gastrectomy and open distal gastrectomy. On the other hand, in the national health insurance system, the operation fee of open distal gastrectomy was USD 6,637 as compared to USD 7,586 for laparoscopy-assisted distal gastrectomy. In spite of the USD 949 difference in the operation fee, the use of disposable instruments for laparoscopy-assisted distal gastrectomy results in a deficit of USD 1,500 over open distal gastrectomy. Conclusion: In spite of the medical superiority of laparoscopy-assisted distal gastrectomy over open distal gastrectomy (if a skilled surgeon operates) as less invasive surgery, laparoscopy-assisted distal gastrectomy is associated with less financial benefit to the hospital as compared to open distal gastrectomy in the current Japanese health insurance system.

Copyright $\odot 2010$ S. Karger AG, Basel

\section{Introduction}

In Japan, health insurance is mandatory and covers virtually all residents of Japan to offer equally medical care. On the other hand, growth of national health care expenditure is a major problem with financial difficulty

\section{KARGER}

Fax +4161306 1234 E-Mail karger@karger.ch www.karger.com
(C) 2010 S. Karger AG, Basel

0253-4886/10/0275-0343\$26.00/0

Accessible online at:

www.karger.com/dsu
Yoshiyuki Hoya

Department of Surgery, Daisan Hospital, Jikei University School of Medicine

4-11-1, Izumihon-cho, Komae-shi

Tokyo 201-8601 (Japan)

Tel. +81 33480 1151/3251, Fax +81 33480 8295, E-Mail hoya@jikei.ac.jp 
and burden confronting the national government. Although most hospitals in Japan are nonprofit organizations, profit associated with the surgical procedure is an important issue.

Generally, if a skilled surgeon operates, the medical superiority of laparoscopy-assisted distal gastrectomy over open distal gastrectomy is admitted from a lot of reference documents. Recently, the minimally invasive surgery with laparoscopy for advanced gastric cancer has often been performed [1], and the Japanese social insurance system accepted the claim of Japanese surgeons and changed the cost of laparoscopy-assisted distal gastrectomy on April 1, 2006, 2008 and 2010. However, the cost of disposable instruments is only partly covered by national health insurance in Japan. In this study, we examined the utility and problems of the laparoscopy-assisted distal gastrectomy for gastric cancer with special emphasis on socioeconomic issue.

\section{Subjects and Methods}

We compared open distal gastrectomy and laparoscopy-assisted distal gastrectomy for the clinical benefit, quality of life, and problems of operation cost by the reference documents in which the difference between open distal gastrectomy and laparoscopyassisted distal gastrectomy was examined in detail. The reference documents retrieved by the key words 'gastric, cancer, laparoscopic, surgery' were 22 in PubMed with the following limits activated: Humans, Clinical Trial, Meta-Analysis, Randomized Controlled Trial, Review, English, Core clinical journals, published between January 2000 and December 2009 [2-23]. Data regarding the following factors were considered about the clinical benefit and quality of life: operation time, blood loss, hospitalization days, duration of fasting after operaton, number of excised lymph nodes, incidence of postoperative complication. The problems of operation cost were considered by simulating the material used for each operation, and calculating the operation fee under the national health insurance system in Japan.

\section{Results}

According to the reference documents retrieved in this study, the operation time of laparoscopy-assisted distal gastrectomy is longer than that of open distal gastrectomy. However, if performed by skillful surgeons, the blood loss of laparoscopy-assisted distal gastrectomy is less, and the hospitalization days as well as the duration of fasting after laparoscopy-assisted distal gastrectomy are shorter than with open distal gastrectomy. It is reported that the number of excised lymph nodes and the incidence of postoperative complication of laparoscopy-
Table 1. Clinical features of laparoscopy-assisted distal gastrectomy as compared with open distal gastrectomy (if performed by skillful surgeons)

\begin{tabular}{ll}
\hline Operation time & longer \\
Blood loss & less \\
Wound pain & less \\
Hospitalization days & shorter \\
Duration of fasting after operation & shorter \\
Number of excised lymph nodes & same \\
Incidence of postoperative complication & same \\
\hline
\end{tabular}

Table 2. Operation fee (USD) for distal partial gastrectomy for gastric cancer after April 2010

\begin{tabular}{lll}
\hline & Open & $\begin{array}{l}\text { Laparoscopy- } \\
\text { assisted }\end{array}$ \\
\hline $\begin{array}{ll}\text { Operation fee (basic charge) } \\
\text { Additional fee }\end{array}$ & 5,587 & 6,236 \\
$\quad \begin{array}{l}\text { Circular stapler } \\
\text { Linear stapler }\end{array}$ & $550(\times 1)$ & $550(\times 1)$ \\
$\quad$ Ultrasonic surgical knife, etc. & $\begin{array}{l}250(\times 2) \\
\text { Needless }\end{array}$ & $250(\times 2)$ \\
\cline { 2 - 3 } Total operation fee & 6,637 & 7,586 \\
\hline
\end{tabular}

assisted distal gastrectomy are the same as for open distal gastrectomy (table 1). There was the same tendency about the clinical profit and the disadvantage of laparoscopyassisted distal gastrectomy in the reference documents retrieved in this study. On the other hand, the open distal gastrectomy operation fee (basic charge) of distal partial gastrectomy for gastric cancer is USD 5,587 and the laparoscopy-assisted distal gastrectomy fee is USD 6,236, and the additional fee for disposable instruments such as circular staplers (USD $550 \times 1$ ), linear staplers (open distal gastrectomy: USD $250 \times 3$, laparoscopy-assisted distal gastrectomy: USD $250 \times 4$ ), and USD 300 for the ultrasound scalpel items including LigaSure vessel sealing system became refundable from the insurance (in April 2008 for laparoscopy-assisted distal gastrectomy, in April 2010 for open distal gastrectomy). Therefore, the operation fee of open distal gastrectomy is USD 6,637, and that of laparoscopy-assisted distal gastrectomy is USD 7,586 (using 1 circular stapler and 2 linear staplers) (table 2). Many disposable operation equipments are required to perform laparoscopy-assisted distal gastrectomy (table 3). Therefore, the operation fee of laparoscopy- 
Table 3. Disposable instruments required for open distal gastrectomy and laparoscopy-assisted distal gastrectomy: standard price (USD)

\begin{tabular}{lcc}
\hline & Open & $\begin{array}{l}\text { Laparoscopy- } \\
\text { assisted }\end{array}$ \\
\hline Company A & \\
GIA (instrument) & 370 & 370 \\
GIA (SULU) & 280 & 280 \\
DSTEEA & 740 & 740 \\
LAPDISC & & 200 \\
BLUNTPORT & & 150 \\
VERSASTEP 12 mm & & $162(\times 2)$ \\
VERSASTEP 5 mm & & $140(\times 2)$ \\
AutoSonix & & 480 \\
LigaSure Atlas & 820 \\
Total cost & 1,390 & 3,644 \\
\hline Company B & & \\
Linear cutter & 310 & 310 \\
Linear cutter, reload & 250 & 250 \\
ILS (SDH) & 570 & 570 \\
MULTI-FLAPGATE & & 200 \\
Blunt tip trocar & & 143 \\
Bladeless trocar, 10/12 mm & & $155(\times 2)$ \\
Bladeless trocar, 5 mm & & $125(\times 2)$ \\
Harmonic scalpel & & 830 \\
LigaSure atlas & & 820 \\
Total cost & & 3,683 \\
\cline { 2 - 3 } & 1,130 & \\
\hline & & \\
\hline
\end{tabular}

assisted distal gastrectomy is USD 949 higher than that of open distal gastrectomy, but the operation profit decrease is about USD 1,500 under the revised national health insurance system after April 1, 2010 in Japan (table 4).

\section{Discussion}

If used by skilled operators, laparoscopy-assisted distal gastrectomy is more useful than open distal gastrectomy as minimal wound surgery to make the hospitalization days short and to reduce the cost of medical care [24-35]. However, the cost of the disposable surgical instruments is not fully covered by health insurance in Japan. The hospital cannot charge medical treatment expenses exceeding the limit set by the national health insurance to the patient. Therefore, the hospital has to defray the operation cost exceeding the ceiling set by the national health insurance payment.

Disadvantage of Laparoscopy-Assisted Distal Gastrectomy
Table 4. Loss for the hospital per case of laparoscopy-assisted distal gastrectomy (USD)

\begin{tabular}{llll}
\hline & Open & $\begin{array}{l}\text { Laparoscopy- Differ- } \\
\text { assisted }\end{array}$ & ence \\
\hline $\begin{array}{l}\text { Company A } \\
\quad \text { Total operation fee }\end{array}$ & 6,637 & 7,586 & \\
$\quad \begin{array}{l}\text { Disposable instruments price } \\
\quad\end{array}$ & 1,390 & 3,644 & \\
$\quad \begin{array}{l}\text { Economic burden } \\
\text { to the hospital }\end{array}$ & 5,247 & 3,942 & 1,305 \\
$\begin{array}{l}\text { Company B } \\
\quad \text { Total operation fee }\end{array}$ & 6,637 & 7,586 & \\
$\quad \begin{array}{l}\text { Disposable instruments price } \\
\text { Economic burden }\end{array}$ & 1,130 & 3,683 & \\
$\quad$ to the hospital & 5,507 & 3,903 & 1,604 \\
\hline
\end{tabular}

The cost reduction measures when operating on laparoscopy-assisted distal gastrectomy under the national health insurance system in Japan include the use of cheap disposable or reusable instruments and avoidance of the use of LigaSure and disposable instruments as much as possible [36].

At present, the operation fee has been excluded in the inclusive payment on the new system called the Diagnosis Procedure Combination (DPC) [37] that begun in 2003 at 80 private and public university hospitals, a public cancer hospital, and a public cardiac care hospital. However, the hospitals have defrayed the cost of disposable operation equipment that exceeds the health insurance payment. From the socioeconomic point of view, the selection of surgical procedures should include considerations of the cost benefit and the net profit except instrument expenditure. Moreover, the surgeon should spend time and labor in the improvement of not only short-term quality of life such as minimally wound surgery, but also mid/longterm quality of life and survival rate.

In conclusion, laparoscopy-assisted distal gastrectomy is superior to open distal gastrectomy as a less-invasive surgery but is associated with decreased hospital profit. Laparoscopy-assisted distal gastrectomy may be expected to develop further outside the national health insurance system in Japan. 


\section{References}

1 Otsuka K, Murakami M, Aoki T, Tajima Y, Kaetsu T, Lefor AT: Minimally invasive treatment of stomach cancer. Cancer J 2005; 11:18-25.

-2 Cho GS, Kim W, Kim HH, Ryu SW, Kim MC, Ryu SY: Multicentre study of the safety of laparoscopic subtotal gastrectomy for gastric cancer in the elderly. Br J Surg 2009;96:14371442 .

3 Jeong GA, Cho GS, Kim HH, Lee HJ, Ryu SW, Song KY: Laparoscopy-assisted total gastrectomy for gastric cancer: a multicenter retrospective analysis. Surgery 2009; 146: 469-474.

4 Gervaz P, Huber O, Morel P: Surgical management of gastrointestinal stromal tumours. Br J Surg 2009;96:567-578

$\checkmark 5$ Choh MS, Madura JA 2nd: The role of minimally invasive treatments in surgical oncology. Surg Clin North Am 2009;89:53-77.

6 Kim YW, Baik YH, Yun YH, Nam BH, Kim $\mathrm{DH}$, Choi IJ, Bae JM: Improved quality of life outcomes after laparoscopy-assisted distal gastrectomy for early gastric cancer: results of a prospective randomized clinical trial. Ann Surg $2008 ; 248: 721-727$.

7 Dholakia C, Gould J: Minimally invasive resection of gastrointestinal stromal tumors. Surg Clin North Am 2008;88:1009-1018.

$\checkmark 8$ Huguet KL, Rush RM Jr, Tessier DJ, Schlinkert RT, Hinder RA, Grinberg GG, Kendrick ML, Harold KL: Laparoscopic gastric gastrointestinal stromal tumor resection: the mayo clinic experience. Arch Surg 2008;143:587-590.

-9 Greene FL, Kercher KW, Nelson H, Teigland CM, Boller AM: Minimal access cancer management. CA Cancer J Clin 2007;57: 130-146.

-10 Kim HJ, D’Angelica M, Hiotis SP, Shoup M, Weber SM: Laparoscopic staging for liver, biliary, pancreas, and gastric cancer. Curr Probl Surg 2007;44:228-269.

- 11 Kitano S, Shiraishi N, Uyama I, Sugihara K, Tanigawa N, Japanese Laparoscopic Surgery Study Group: A multicenter study on oncologic outcome of laparoscopic gastrectomy for early cancer in Japan. Ann Surg 2007;245: 68-72.

-12 Clark CJ, Thirlby RC, Picozzi V Jr, Schembre DB, Cummings FP, Lin E: Current problems in surgery: gastric cancer. Curr Probl Surg 2006;43:566-670.

13 Rohatgi PR, Mansfield PF, Crane CH, Wu TT, Sunder PK, Ross WA, Morris JS, Pisters PW, Feig BW, Gunderson LL, Ajani JA: Surgical pathology stage by American Joint Commission on Cancer criteria predicts patient survival after preoperative chemoradiation for localized gastric carcinoma. Cancer 2006;107:1475-1482.
4 Rosen MJ, Heniford BT: Endoluminal gastric surgery: the modern era of minimally invasive surgery. Surg Clin North Am 2005;85: 989-1007.

15 Abe N, Mori T, Takeuchi H, Yoshida T, Ohki A, Ueki H, Yanagida O, Masaki T, Sugiyama M, Atomi Y: Laparoscopic lymph node dissection after endoscopic submucosal dissection: a novel and minimally invasive approach to treating early-stage gastric cancer Am J Surg 2005;190:496-503.

16 Huscher CG, Mingoli A, Sgarzini G, Sansonetti A, Di Paola M, Recher A, Ponzano C Laparoscopic versus open subtotal gastrectomy for distal gastric cancer: five-year results of a randomized prospective trial. Ann Surg 2005;241:232-237.

17 Kitano S, Shiraishi N: Minimally invasive surgery for gastric tumors. Surg Clin North Am 2005;85:151-164.

18 Norton JA, Jensen RT: Resolved and unresolved controversies in the surgical management of patients with Zollinger-Ellison syndrome. Ann Surg 2004;240:757-773.

19 D’Ugo DM, Pende V, Persiani R, Rausei S, Picciocchi A: Laparoscopic staging of gastric cancer: an overview. J Am Coll Surg 2003; 196:965-974.

20 Kitano S, Shiraishi N, Fujii K, Yasuda K, Inomata M, Adachi Y: A randomized controlled trial comparing open versus laparoscopy-assisted distal gastrectomy for the treatment of early gastric cancer: an interim report. Surgery 2002;131:S306-S311

21 Schuhmacher CP, Fink U, Becker K, Busch R, Dittler HJ, Mueller J, Siewert JR: Neoadjuvant therapy for patients with locally advanced gastric carcinoma with etoposide, doxorubicin, and cisplatinum: closing results after 5 years of follow-up. Cancer 2001; 91:918-927.

22 Cuschieri A: Laparoscopic gastric resection Surg Clin North Am 2000;80:1269-1284.

23 Pratt BL, Greene FL: Role of laparoscopy in the staging of malignant disease. Surg Clin North Am 2000;80:1111-1126.

24 Itabashi Y, Baba T, Kurita T, Kato S, Sasaki M: Laparoscopy-assisted distal gastrectomy for early gastric cancer: our experience. Hirosaki Med J 2003;55:1-6.
25 Migoh SMD, Hasuda KMD, Nakashima KMD, Anai HMD: The benefit of laparoscopy-assisted distal gastrectomy compared with conventional open distal gastrectomy: a case-matched control study. Hepato-Gastroenterology 2003;50:2251-2254.

26 Niitsuma Y, Kawasaki T, Tsukui H, et al: Evaluation of hand-assisted laparoscopic distal gastrectomy for patients with early gastric cancer. J Jpn Assoc Rural Med 2003; 52:717-725.

27 Amaike $\mathrm{H}$, Taniguchi H, Fuji N, et al: current status of laparoscopy-assisted gastrectomy for gastric cancer in Kyoto prefectural Yosanoumi hospital. J Kyoto Pref Univ Med 2004; 113:573-580

28 Inoue S, Uemekita N, Maeshiro T, Miyamoto S, Kitamura M: Indication and limits of laparoscopy assisted gastrectomy. J Jpn Coll Surg 2001;26:1042-1044

29 Shimizu S, Uchiyama A, Mizumoto K, et al: Laparoscopically assisted distal gastrectomy for early gastric cancer: is it superior to open surgery? Surg Endosc 2000;14:27-31.

30 Yano H, Monden T, Kinuta M, et al: The usefulness of laparoscopy-assisted distal gastrectomy in comparison with that of open distal gastrectomy for early gastric cancer. Gastric Cancer 2001;4:93-97.

-31 Mochiki E, Nakabayashi T, Kamimura H, Haga N, Asao T, Kuwano H: Gastrointestinal recovery and outcome after laparoscopy-assisted versus conventional open distal gastrectomy for early gastric cancer. World J Surg 2002;26:1145-1149.

32 Adachi Y, Shiraishi N, Shiromizu A, Bandoh T, Aramaki M, Kitano S: Laparoscopy-assisted Billroth I gastrectomy compared with conventional open gastrectomy. Arch Surg 2000;135:806-810.

33 Kasai Y, Fujiwara M, Nakao A: Laparoscopic distal gastrectomy for early gastric cancer. Gastroenterology 2001;33:369-375.

34 Kojima K, Yamashita T, Yamada H, Kono T, Sugihara K: Dose laparoscopy-assisted gastrectomy improve the long-term of QOL for the patients with early gastric cancer? Surgical Therapy 2003;88:356-358.

35 Tanimura S, Higashino M, Fukunaga Y, Kishida S, Nishikawa M, Ogata A: Laparoscopic distal gastrectomy for advanced gastric cancer. Gastroenterol Surg 2004;27:215219.

-36 Adachi Y, Shiraishi N, Ikebe K, Aramaki M, Bandoh T, Kitano S: Evaluation of the cost for laparoscopic-assisted Billroth I gastrectomy. Surg Endosc 2001;15:932-936.

-37 Ishikawa K, Yamamoto M, Kishi DT, Nabeshima T: New prospective payment system in Japan. Am J Health Syst Pharm 2005;62: 1617-1619. 